Check for updates

Cite this: Chem. Sci., 2019, 10, 3481

๑ All publication charges for this article have been paid for by the Royal Society of Chemistry

Received 17th December 2018 Accepted 27th January 2019

DOI: $10.1039 / \mathrm{c} 8 \mathrm{sc} 05618 \mathrm{~h}$

rsc.li/chemical-science

\section{ppm Pd-catalyzed, Cu-free Sonogashira couplings in water using commercially available catalyst precursors $\dagger$}

\author{
Bo Jin, (D) ${ }^{a}$ Fabrice Gallou, (D) ${ }^{b}$ John Reilly (D) ${ }^{c}$ and Bruce H. Lipshutz (D) *a \\ A new catalyst that derives from commercially available precursors for copper-free, Pd-catalyzed \\ Sonogashira reactions at the sustainable ppm level of precious metal palladium under mild aqueous \\ micellar conditions has been developed. Both the palladium pre-catalyst and ligand are commercially \\ available, bench stable, and highly cost-effective. The catalyst is applicable to both aryl- and heteroaryl- \\ bromides as educts. A wide range of functional groups are tolerated and the aqueous reaction medium \\ can be recycled. An application to a key intermediate associated with an active pharmaceutical \\ ingredient (ponatinib) is discussed.
}

\section{Introduction}

Development of a Pd-catalyzed process that leads to coupling between a terminal alkyne and an aromatic/heteroaromatic ring by Sonogashira and co-workers back in 1975 (ref. 1) focused on providing an alternative to the corresponding reaction mediated solely by copper, the Castro-Stevens coupling. Today, Sonogashira couplings no longer require use of both catalytic $\mathrm{Pd}$ and $\mathrm{Cu}$; rather, catalytic Pd alone is quite sufficient when appropriately complexed by a ligand more modern than the $\mathrm{Ph}_{3} \mathrm{P}$ originally employed. Among the array of highly valued Pdcatalyzed coupling reactions, Sonogashira couplings remain unique due to the involvement of an sp carbon center, and are widely utilized in the pharmaceutical industry ${ }^{2}$ and in natural products total synthesis, ${ }^{3}$ as well as in the construction of organic materials. ${ }^{4}$ Nonetheless, improvements continue, looking to enhance functional group tolerance and yields, avoidance of occasional harsh reaction conditions and problematic workups, as well as avoidance of more expensive and sensitive coupling partners (e.g., iodides). ${ }^{2 c, 5}$ Also looming big is the up front cost of $\mathrm{Pd}$ catalysts and associated expensive ligands, typically used in the 1-5 mol\% range, while at the back end, required removal of residual metal embedded within the desired products is to be expected and must be removed especially when working towards an API. ${ }^{6}$ Moreover, from the environmental perspective, most Sonogashira couplings are run in organic solvents, without recycling of either the medium or

${ }^{a}$ Department of Chemistry and Biochemistry, University of California, Santa Barbara, California, 93106, USA.E-mail: lipshutz@chem.ucsb.edu

${ }^{b}$ Novartis Pharma AG, CH-4057 Basel, Switzerland

${ }^{c}$ Novartis Institute for Medical Research, Cambridge, Massachusetts, 02139, USA

$\dagger$ Electronic supplementary information (ESI) available. See DOI: $10.1039 / \mathrm{c} 8 \mathrm{sc} 05618 \mathrm{~h}$ precious metal catalyst. ${ }^{7}$ Use of these traditional reaction parameters dramatically increase levels of both the organic and aqueous waste to be expected, and fail to acknowledge the endangered status of platinoids. ${ }^{8}$

Previously, we disclosed a sustainable technology for ppm level Pd-catalyzed Sonogashira cross-couplings based on the new ligand HandaPhos, enabled by aqueous micellar catalysis. ${ }^{9}$ This approach reduces usage of Pd to a sustainable $1000 \mathrm{ppm}$ (0.1 mol\%) loading, without participation by copper. At issue, however, is the preparation of HandaPhos, ${ }^{\mathbf{1 0}}$ following the sequence first outlined by Boehringer-Ingelheim, ${ }^{\mathbf{1 1}}$ requiring 10 steps. Herein we describe an alternative technology that maintains the ppm level of palladium catalysis under aqueous micellar conditions, but which benefits from readily available precursors that are items of commerce and hence, makes this approach more accessible and far more economically attractive.

\section{Results and discussion}

Based on our earlier work describing room temperature Sonogashira reactions in aqueous nanoreactors derived from the designer surfactant PTS, ${ }^{12}$ we re-examined the BRIDP family of ligands developed by Takasago. ${ }^{13}$ Screening initially at $1300 \mathrm{ppm}$ $(0.13 \mathrm{~mol} \%)$ of various sources of $\mathrm{Pd}$ in $2^{\text {nd }}$ generation micellar media (TPGS-750-M/ $\mathrm{H}_{2} \mathrm{O}$ ) indicated that, yet again, cBRIDP (Scheme 1) imparts the greatest reactivity (also see ESI $\dagger$ ).

The source of Pd was also crucial for Sonogashira couplings at the ppm level of this metal. Hence, increasing the lipophilicity of the allylic ligand on Pd (by going from allyl to crotyl to cinnamyl), presumably increasing the binding constant of this catalyst to the inner micellar core ${ }^{\mathbf{1 4}}$ afforded the most effective and active catalyst system. The increased bulkiness at the 1-position may also play an activating role by minimizing formation of less reactive $\operatorname{Pd}(\mathrm{I})$ dimeric species, as noted 

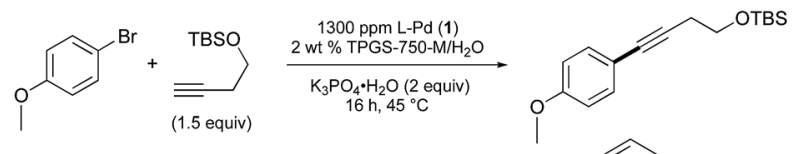

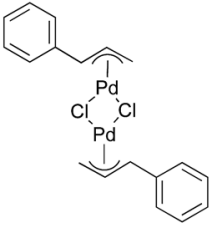

$\left[\mathrm{Pd}(\text { cinnamyl) } \mathrm{Cl}]_{2}\right.$

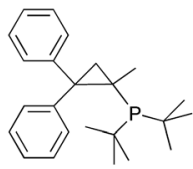

CBRIDP

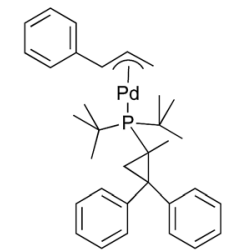

1; $\mathrm{Pd}($ cinnamyl)(CBRIDP)Cl
Scheme 1 Structures of cBRIDP ligand, pre-catalyst $\left[\mathrm{Pd}\left(\right.\right.$ cinnamyl) $\mathrm{Cl}_{2}$ and in situ-derived catalyst 1 used in this model reaction.

previously by Hazari $^{15}$ and Colacot. ${ }^{16}$ The most effective combination ultimately led to use of a $3: 1$ ratio of ligand to palladium. $\mathrm{K}_{3} \mathrm{PO}_{4} \cdot \mathrm{H}_{2} \mathrm{O}$ was found to be the best base for liquid starting materials. However, when the bromide or terminal alkyne is a solid, the resulting viscosity of the medium caused by the (solid) base was found to inhibit stirring. In this case the base could be readily changed to $\mathrm{Et}_{3} \mathrm{~N}$. From these reaction parameters, a variety of substrate combinations using $0.05 \mathrm{~mol} \%$ of dimeric $[\mathrm{PdCl}(\text { cinnamyl })]_{2}$ (i.e., $\left.1000 \mathrm{ppm}\right)$ was screened (Table 1(A)). At these low levels of handling, the catalyst was added to the reaction vial in the form of a pre-mixed THF stock solution, after which the small amounts of THF were easily removed under vacuum. For substrates that appeared to be more challenging (e.g., slower or incomplete reactions), $1500 \mathrm{ppm}(0.15 \mathrm{~mol} \%)$ of the same palladium pre-catalyst was found to be very effective (Table $1(\mathrm{~B})$ ).

Judging from the results shown in Table 1, this new catalytic system displays high functional group compatibility. Heteroaryl bromides leading to 2-, 3-, and 4-substituted pyridines $(\mathbf{3}, \mathbf{4}, \mathbf{8}$, 11, 19), quinoline (6), furan (5), benzothiophene (10), thiophene (15), and indole (16) were all converted to their corresponding coupling products in good-to-excellent yields. Similarly, sensitive functional groups are tolerant, as in products containing chloro $(9,11,12,14)$, enyne $(3)$, fluoro $(3,5,8,9)$, trifluoromethyl $(12,20)$, ketone $(4)$, aldehyde $(5,14,15)$, thioether $(2)$, amide $(7)$, acetal $(9,17,18)$, hydroxyl $(6)$, ester $(\mathbf{1 7}, 19)$ and carbamate $(\mathbf{1 6})$ residues. Product 13 could be readily generated in gram quantities (i.e., on a $5 \mathrm{mmol}$ scale). Notably, this gram-scale reaction could be carried out with solid palladium pre-catalyst and ligand; i.e., without pre-dissolution in THF.

The products of these reactions ${ }^{\mathbf{1 7}}$ produce alkynes attached to aromatic or heteroaromatic rings, which represent electronwithdrawing groups that may provide additional activation useful for secondary processes. For example, as illustrated in Scheme 2 below, a 2-step, 1-pot sequence, initiated by a Sonogashira cross-coupling, is then followed (without isolation or added base) by a selective $S_{N} A r$ reaction to install a diaminecontaining residue common to many biologically active compounds. ${ }^{18}$ Both reactions take place in virtually quantitative yields to afford internal alkyne $\mathbf{2 3}$.

At typical loadings of $\mathrm{Pd}$ in the $1-5 \mathrm{~mol} \%$ range, residual amounts of $\mathrm{Pd}$ in the hundreds of ppm range are to be
Table 1 Representative Sonogashira couplings in water catalyzed by (A) 1000 or (B) 1500 ppm Pd ${ }^{a, b}$

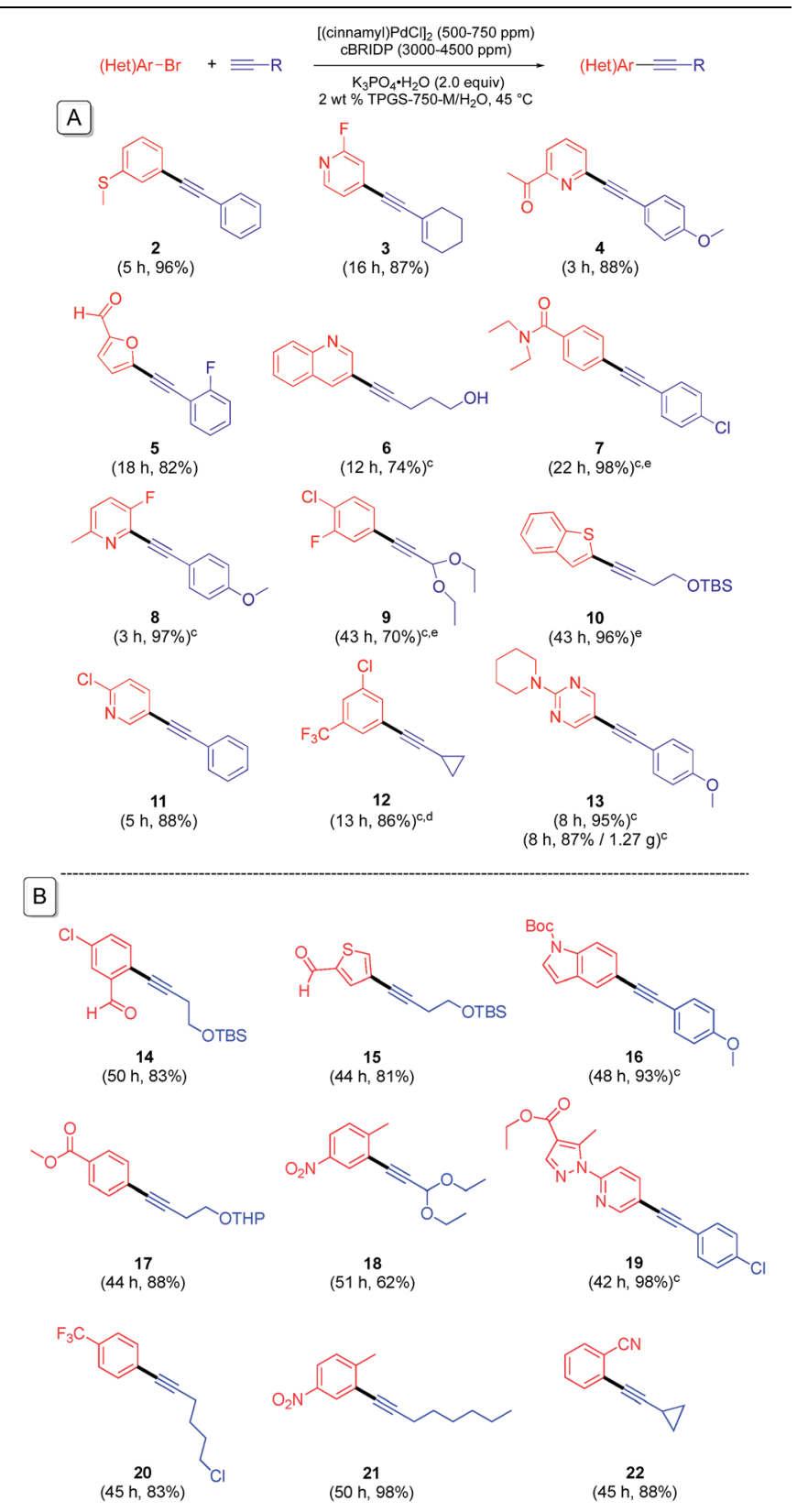

${ }^{a}$ Conditions: bromide $(0.5 \mathrm{mmol}),[(\text { cinnamyl }) \mathrm{PdCl}]_{2}(0.05 \mathrm{~mol} \%)$, cBRIDP $(0.30 \mathrm{~mol} \%)$, terminal alkyne $(0.60 \mathrm{mmol}), \mathrm{K}_{3} \mathrm{PO}_{4} \cdot \mathrm{H}_{2} \mathrm{O}(2.0$ equiv.), TPGS-750-M/ $\mathrm{H}_{2} \mathrm{O}(2 \mathrm{wt} \%, 1 \mathrm{~mL}), 45{ }^{\circ} \mathrm{C}, \mathrm{Ar} .{ }^{b}$ Isolated yield. ${ }^{c} \mathrm{Et}_{3} \mathrm{~N}$ (2.0 equiv.) as base. ${ }^{d}$ Reaction run at $35{ }^{\circ} \mathrm{C}, 1.1$ equiv. of terminal alkyne used. ${ }^{e} 1.5$ equiv. of terminal alkyne used.

expected, requiring removal especially when associated with an API. Process chemists have developed systematic methods ${ }^{6,19}$ so as to meet FDA regulations for palladium allowance. $^{20}$ ICP-MS tests indicated that products from these ppm level Pd-catalyzed Sonogashira couplings contain less than $1 \mathrm{ppm}$ when run at a loading of $1000 \mathrm{ppm}$ palladium (Scheme 3), amounts which are well below acceptable levels. 

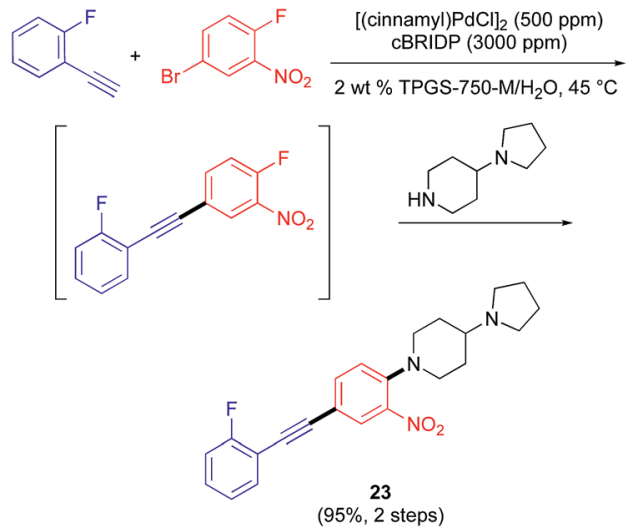

Scheme 2 2-Step, 1-pot process using an initial 1000 ppm Pd-catalyzed Sonogashira coupling in water.

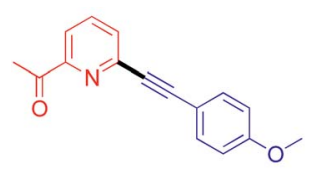

$4(3 \mathrm{~h}, 88 \%)$

$0.1 \mathrm{~mol} \%$ palladium residual $\mathrm{Pd}<1 \mathrm{ppm}$

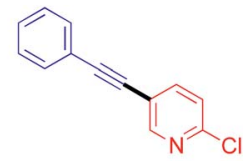

$11(5 \mathrm{~h}, 88 \%)$

$0.1 \mathrm{~mol} \%$ palladium

residual $\mathbf{P d}=1 \mathrm{ppm}$
Scheme 3 ICP-MS analyses of residual palladium in products 4 and 11 .

Other features associated with this ppm Pd chemistry in water include the facile recycling of the aqueous TPGS-750-M solution being used, and the low $E$ factor suggestive of the limited amounts of waste being created. Rather than using an "in flask" extraction process that requires only small amounts of an organic solvent, as done in our previous study, ${ }^{21}$ an even lower $E$ factor can be achieved by simply filtering the solid product that precipitates out from the reaction. The aqueous filtrate containing the surfactant, engineered to remain in the water, can be collected and used for subsequent couplings. In these cases, the crude product was washed with small amounts of DI water and air-dried. Hence, the only organic solvent required for this reaction is $\mathrm{THF}$, used to prepare the stock solution of catalyst. The resulting $E$ factor based on this reaction, as a measure of "greenness", ${ }^{22}$ is only 0.78 (see ESI $\dagger$ ). As indicated previously with respect to the gram-scale reaction, preparation of a stock solution is actually not necessary for this reaction, in which case the $E$ factor goes to zero. The aqueous

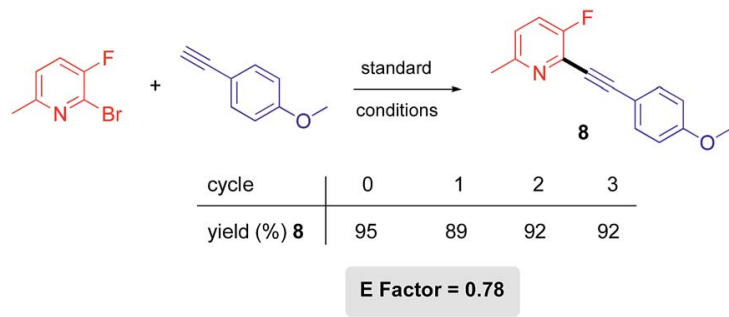

Scheme 4 Recycling study and E factor determination.
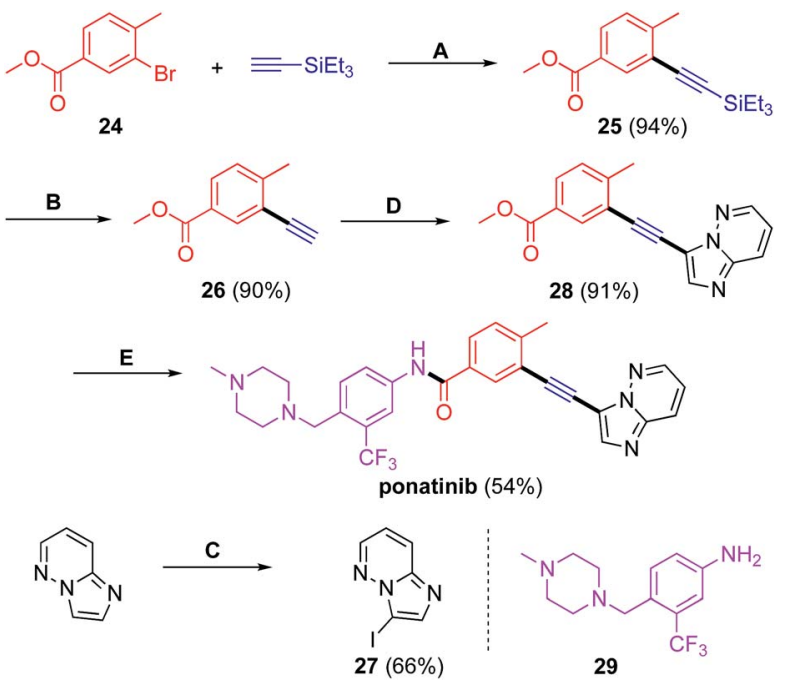

Scheme 5 Synthesis of ponatinib. Conditions: step: (A) 24 (1.0 equiv.), (triethylsilyl)acetylene (2.0 equiv.), [(cinnamyl) PdCl $]_{2}(0.075 \mathrm{~mol} \%)$, cBRIDP (0.45 mol\%), Et $3 \mathrm{~N}$ (2.0 equiv.), $0.5 \mathrm{M}$ in 2 wt\% TPGS-750-M/ $\mathrm{H}_{2} \mathrm{O}, 45^{\circ} \mathrm{C}, \mathrm{Ar}, 45 \mathrm{~h}$; step: (B) 25 (1.0 equiv.), $\mathrm{K}_{2} \mathrm{CO}_{3}$ (20 mol\%), $0.5 \mathrm{M}$ in $1: 1 \mathrm{MeOH} / \mathrm{THF}, 45^{\circ} \mathrm{C}, 5 \mathrm{~h}$; step (C): imidazo[1,2-b]pyridazine (1.0 equiv.), $\mathrm{N}$-iodosuccinimide (1.2 equiv.), $0.53 \mathrm{M}$ in DMF, $80{ }^{\circ} \mathrm{C}, \mathrm{Ar}$, overnight; step (D): 27 (1.0 equiv.), 26 (1.2 equiv.), [(cinnamyl) $\mathrm{PdCl}{ }_{2}$ (0.075 mol\%), cBRIDP (0.45 mol\%), Et ${ }_{3} \mathrm{~N}$ (2.0 equiv.), $0.5 \mathrm{M}$ in $2 \mathrm{wt} \%$ TPGS-750- $\mathrm{M} / \mathrm{H}_{2} \mathrm{O}, 45{ }^{\circ} \mathrm{C}, \mathrm{Ar}, 47 \mathrm{~h}$. Step (E): 28 (1.0 equiv.), 4-(4methyl-piperazinomethyl)-3-(trifluoromethyl)aniline (1.0 equiv.), KOt-Bu (2.0 equiv.), $0.17 \mathrm{M}$ in THF, rt, $\mathrm{Ar}, 12 \mathrm{~h}$.

solution containing the surfactant was then recycled three times with the addition of $1000 \mathrm{ppm}$ palladium plus ligand for each (see $\mathrm{ESI} \dagger$ ), giving rise to consistently high isolated yields (Scheme 4).

As an illustration of the potential for this coupling chemistry, a key intermediate 28 in the synthesis of the FDA approved tyrosine-kinase inhibitor ponatinib (Iclusig ${ }^{\circledR}$ ). ${ }^{23}$ is shown in Scheme 5, involving two Sonogashira couplings. The starting material, bromide $\mathbf{2 4}$, was first coupled with TES-acetylene under standard reaction conditions using $750 \mathrm{ppm}$ of the same catalyst derived from $[\mathrm{PdCl}(\text { cinnamyl })]_{2}$ and cBRIDP. The TES group was then removed using a catalytic amount of potassium carbonate in a mixture of THF and methanol. ${ }^{24}$ The second Sonogashira coupling between the substituted phenylacetylene 26 and 3-iodoimidazo[1,2-b]pyridazine 27, readily prepared from imidazo[1,2- $b]$ pyridazine upon treatment with NIS, proceeded smoothly under standard reaction conditions to afford intermediate 28 in excellent overall yield (77\%). The targeted API was then realized by simple exposure of 28 to the aniline partner 29 in dry THF containing $\mathrm{KO}-t-\mathrm{Bu}$, following the procedure in the Takeda patent. ${ }^{25}$

\section{Conclusions}

In summary, a sustainable, Cu-free, ppm level Pd-catalyzed Sonogashira reaction has been developed that represents the new 'state-of-the-art' in such valued cross-couplings, especially from the green chemistry perspective. It relies upon a combination of commercially available palladium pre-catalyst and 
ligand, leading to an in situ-formed highly active catalyst that is effective with aryl/heteroaryl halides at the $0.10-0.15 \mathrm{~mol} \%$ level of endangered palladium at $45{ }^{\circ} \mathrm{C}$ in water as the reaction medium. Products can be isolated in many cases by simple filtration, thus entirely avoiding organic solvents throughout the process. In addition to documenting the potential for scale up, an application to a timely active pharmaceutical ingredient showcases this environmentally responsible and sustainable technology.

\section{Conflicts of interest}

There are no conflicts to declare.

\section{Acknowledgements}

Financial support provided by NSF (GOALI SusChEM 1566212) and Novartis is warmly acknowledged.

\section{Notes and references}

1 (a) K. Sonogashira, Y. Tohda and N. Hagihara, Tetrahedron Lett., 1975, 16, 4467. See also (b) New Trends in CrossCoupling: Theory and Applications, ed. T. J. Colacot, RSC, Cambridge, UK, 2015; (c) Metal-Catalyzed Cross-Coupling Reactions, ed. A. de Meijere and F. Diederich, Wiley-VCH, Weinheim, 2004, vol. 1 \& 2; (d) C. C. C. J. Seechurn, M. O. Kitching, T. J. Colacot and V. Snieckus, Angew. Chem., Int. Ed., 2012, 51, 5062.

2 (a) F. F. Wagner and D. L. Comins, J. Org. Chem., 2006, 71, 8673; (b) K. Nishimura and M. Kinugawa, Org. Process Res. Dev., 2012, 16, 225; (c) J. B. Sperry, R. M. Farr, M. Levent, M. Ghosh, S. M. Hoagland, R. J. Varsolona and K. Sutherland, Org. Process Res. Dev., 2012, 16, 1854; (d) Z. J. Song, D. M. Tellers, P. G. Dormer, D. Zewge, J. M. Janey, A. Nolting, D. Steinhuebel, S. Oliver, P. N. Devine and D. M. Tschaen, Org. Process Res. Dev., 2014, 18, 423.

3 (a) S. López, F. Fernandez-Trillo, P. Midon, L. Castedo and C. Saa, J. Org. Chem., 2006, 71, 2802; (b) F. Manoni, C. Rumo, L. Li and P. G. Harran, J. Am. Chem. Soc., 2018, 140, 1280; (c) J. Zhou, B. Gao, Z. Xu and T. Ye, J. Am. Chem. Soc., 2016, 138, 6948; (d) M. J. Sowden and M. S. Sherburn, Org. Lett., 2017, 19, 636.

4 (a) A. Idelson, C. Sterzenbach, S.-S. Jester, C. Tschierske, U. Baumeister and S. Höger, J. Am. Chem. Soc., 2017, 139, 4429; (b) X. Zhuang, D. Gehrig, N. Forler, H. Liang, M. Wagner, M. R. Hansen, F. Laquai, F. Zhang and X. Feng, Adv. Mater., 2015, 27, 3789; (c) Y. S. L. V. Narayana, S. Basak, M. Baumgarten, K. Mellen and R. Chandrasekar, Adv. Funct. Mater., 2013, 23, 5875.

5 V. Kozell, M. McLaughlin, G. Strappaveccia, S. Santoro, L. A. Bivona, C. Aprile, M. Gruttadauria and L. Vaccaro, ACS Sustainable Chem. Eng., 2016, 4, 7209.

6 K. Königsberger, G.-P. Chen, R. R. Wu, M. J. Girgis, K. Prasad, O. Repič and T. J. Blacklock, Org. Process Res. Dev., 2003, 7, 733.
7 (a) R. Chinchilla and C. Nájera, Chem. Rev., 2007, 107, 874; (b) R. Chinchilla and C. Nájera, Chem. Soc. Rev., 2011, 40, 5084 .

8 J. Kooroshy, C. Meindersma, R. Podkolinski, M. Rademaker, T. Sweijs, A. Diederen, M. Beerthuizen and S. de Goede, Scarcity of Minerals Hague Centre for Strategic Studies, Hague Centre for Strategic Studies, 2009.

9 S. Handa, J. D. Smith, Y. Zhang, B. S. Takale, F. Gallou and B. H. Lipshutz, Org. Lett., 2018, 20, 542.

10 S. Handa, M. P. Andersson, F. Gallou, J. Reilly and B. H. Lipshutz, Angew. Chem., Int. Ed., 2016, 55, 4914.

11 (a) W. Tang, B. Qu, A. G. Capacci, S. Rodriguez, X. Wei, N. Haddad, B. Narayanan, S. Ma, N. Grinberg, N. K. Yee, D. Krishnamurthy and C. H. Senanayake, Org. Lett., 2010, 12, 176; (b) W. Tang, A. G. Capacci, X. Wei, W. Li, A. White, N. D. Patel, J. Savoie, J. J. Gao, S. Rodriguez, B. Qu, N. Haddad, B. Z. Lu, D. Krishnamurthy, N. K. Yee and C. H. Senanayake, Angew. Chem., Int. Ed., 2010, 49, 5879.

12 B. H. Lipshutz, D. W. Chung and B. Rich, Org. Lett., 2008, 10, 3793.

13 K. Suzuki, Y. Hori and T. Kobayashi, Adv. Synth. Catal., 2008, 350, 652.

14 B. H. Lipshutz, Curr. Opin. Green Sustain. Chem., 2018, 11, 1. 15 D. P. Hruszkewycz, D. Balcells, L. M. Guard, N. Hazari and M. Tilset, J. Am. Chem. Soc., 2014, 136, 7300.

16 A. J. DeAngelis, P. G. Gildner, R. Chow and T. J. Colacot, J. Org. Chem., 2015, 80, 6794.

17 In addition to the desired products from these couplings, it is also interesting to question the fate of the cinnamyl (cationic) residue within the $\operatorname{Pd}(\mathrm{II})$ pre-catalyst 1 upon reduction under these reaction conditions. ${ }^{\mathbf{1 6}}$ The most likely outcome, leading to trapping by water (and thus, producing cinnamyl alcohol), was in fact not observed (by careful GC analysis $v s$. an authentic sample). Rather, small amounts of the corresponding acetylated product (using phenyl-acetylene) were identified. This strongly suggests that the conversion of the catalyst 1 to its active $\operatorname{Pd}(0)$ state is taking place inside the hydrophobic micellar core, akin to that seen under traditional conditions in organic solvents, ${ }^{16}$ and not in the (hydrogen-bonded to water) PEG region or the surrounding aqueous medium.

18 (a) N. R. Lee, F. Gallou and B. H. Lipshutz, Org. Process Res. Dev., 2017, 21, 218; (b) N. A. Isley, R. T. H. Linstadt, S. M. Kelly, F. Gallou and B. H. Lipshutz, Org. Lett., 2015, 17, 4734 .

19 (a) Y. Urawa, M. Miyazawa, N. Ozeki and K. Ogura, Org. Process Res. Dev., 2003, 7, 191; (b) J.-P. Huang, X.-X. Chen, S.-X. Gu, L. Zhao, W.-X. Chen and F.-E. Chen, Org. Process Res. Dev., 2010, 14, 939.

20 F.D.A., Q3D Elemental Impurities Guidance for Industry, https:/www.fda.gov/downloads/drugs/guidances/ ucm371025.pdf.

21 B. H. Lipshutz, N. A. Isley, J. C. Fennewald and E. D. Slack, Angew. Chem., Int. Ed., 2013, 52, 10952.

22 R. A. Sheldon, Green Chem., 2007, 9, 1273.

23 W.-S. Huang, C. A. Metcalf, R. Sundaramoorthi, Y. H. Wang, D. Zou, R. M. Thomas, X. T. Zhu, L. S. Cai, D. Wen, S. Y. Liu, 
J. Romero, J. W. Qi, I. Chen, G. Banda, S. P. Lentini, S. Das, Q. H. Xu, J. Keats, F. Wang, S. Wardwell, Y. Y. Ning, J. T. Snodgrass, M. I. Broudy, K. Russian, T. J. Zhou, L. Commodore, N. I. Narasimhan, Q. K. Mohemmad, J. Iuliucci, V. M. Rivera, D. C. Dalgarno, T. K. Sawyer, T. Clackson and W. C. Shakespeare, J. Med. Chem., 2010, 53, 4701.
24 Y. Zhao, A. D. Slepkov, C. O. Akoto, R. McDonald, F. A. Hegmann and R. R. Tykwinski, Chem.-Eur. J., 2005, 11, 321.

25 C. K. Murray, L. W. Rozamus, J. J. Chaber, P. Sharma and S. Kazerani, WO 2014/093583 A2, 2014. 